\title{
Health Service Delivery in China: A Literature Review
}

\author{
by \\ Karen Eggleston ${ }^{a}$, Li Ling ${ }^{b}$, Meng Qingyue ${ }^{c}$, Magnus Lindelow ${ }^{d}$ and Adam Wagstaff ${ }^{d}$ \\ a Economics Department, Tufts University, Medford, MA 02155, USA \\ ${ }^{\mathrm{b}}$ China Center for Economic Research, Peking University, Beijing, China \\ ${ }^{c}$ Centre for Health Management and Policy, Shandong University, Jinan, China \\ ${ }^{\mathrm{d}}$ The World Bank, Washington DC 20433, USA
}

\begin{abstract}
We report the results of a review of the Chinese-language and English-language literatures on service delivery in China, asking how well China's health care providers perform, what determines their performance, and how the government can improve it. We find current performance leaves room for improvement, in terms of quality, responsiveness to patients, efficiency, cost escalation, and equity. The literature suggests that these problems will not be solved by simply shifting ownership to the private sector, or by simply encouraging providers-public and private-to compete with one another for individual patients. By contrast, substantial improvements could be (and in some places have already been) made by changing the way providers are paid-shifting away from fee-for-service and the distorted price schedule toward prospective payments. Active purchasing by insurers could further improve outcomes.
\end{abstract}

Corresponding author: Adam Wagstaff, World Bank, 1818 H Street NW, Washington, D.C. 20433, USA. Tel. (202) 473-0566. Fax (202)-522 1153. Email: awagstaff@worldbank.org.

Keywords: health service delivery; provider payments; China.

\section{World Bank Policy Research Working Paper 3978, August 2006}

The Policy Research Working Paper Series disseminates the findings of work in progress to encourage the exchange of ideas about development issues. An objective of the series is to get the findings out quickly, even if the presentations are less than fully polished. The papers carry the names of the authors and should be cited accordingly. The findings, interpretations, and conclusions expressed in this paper are entirely those of the authors. They do not necessarily represent the view of the World Bank, its Executive Directors, or the countries they represent. Policy Research Working Papers are available online at http://econ.worldbank.org.

Acknowledgements: The authors benefited from the comments of Mr. Fei Zhaohui of the Chinese Ministry of Finance, who was the discussant for this review at a workshop held in Beijing in July 2004, and from the comments on earlier drafts by Dick Meyers of the World Bank. 


\section{INTRODUCTION}

How do China's health care providers perform? What determines their performance? How can the government improve it? To answer these questions, we undertook a review of the Chinese-language and English-language literatures on service delivery in China, as well as looking at lessons from abroad. The review comes at a key moment in China's health reform process. There is broad agreement that the health service delivery system is not functioning well, but there is considerable disagreement about how to fix it. Some argue for turning over the entire system to a free market. Others recall the benefits of a centrally planned health system. The truth—-this paper argues—lies somewhere between these two extreme views.

\section{PROVIDER PERFORMANCE IN CHINA'S HEALTH SECTOR}

Quality is a key dimension of any provider’s performance. Like many countries, China does not have a strong system for monitoring the quality of care. But several indicators suggest quality could be better. The skill of providers is low, especially at the village level. A large-scale study of 46 counties and 781 village doctors in 9 western provinces conducted in 2001 found that $70 \%$ of village doctors had no more than a high school education and had received an average of only 20 months of medical training. ${ }^{1}$

There is widespread evidence of unnecessary care being provided in China, especially drugs. In 1998-99, a study conducted in 4 township health centers and 8 village clinics in Wuxi County of Chongqing and Min County of Gansu concluded that less than 2\% of drug prescriptions were 'rational'. In the case of village clinics, only $0.06 \%$ of drug prescriptions were

deemed reasonable. ${ }^{2}$ Unnecessary care makes for costs that are higher than necessary. For 
example, one study found that $20 \%$ of all expenditure associated with appendicitis and pneumonia treatment was clinically unnecessary. ${ }^{3}$ In the study, as much as one third of drug expenditures were considered to be unnecessary by a panel of reviewing physicians. The panel concluded that, for both conditions, length of stay (LOS) could be reduced by $10-15 \%$ without any adverse effects on health outcomes.

There is some evidence that health care quality in China has improved over time, but these improvements seem to be confined primarily to urban areas. ${ }^{4}$ For patients-especially poor ones-unnecessary expenses associated with low quality can make the difference between health care being affordable and being unaffordable. In some situations, unnecessary care may also have adverse health consequences.

Beyond the apparently low technical quality of care, patients have expressed dissatisfaction about providers’ responsivenes. For example, in a recent sample interview with 642 urban residents, roughly 70\% expressed satisfaction with health care services, and 65\% were satisfied with the attitudes of the health providers. ${ }^{5}$ However, $54 \%$ complained that their doctors were not clear about their disease status, and $4 \%$ said that they or their relatives had open conflict with the health providers (yiliao jiufen).

The efficiency of China's health care providers is also a matter of concern. In recent years, the number of providers has increased while caseload has been falling. Bed-occupancy rates are, as a result, falling, especially in township hospitals where bed occupancy was low to start with. Provider productivity—measured in terms of patients per provider per day—is also falling in rural areas, from a relatively low base. There is also evidence of waste in the use of high-tech equipment. 
A further concern as far as provider performance is concerned is the rapid cost escalation that China's health sector has witnessed in recent years. Costs have risen much faster than per capita income and prices generally. This reflects in part a more complex caseload (less infectious diseases, more NCDs) and the adoption of new technology. Whether costs have risen 'too' fast is not clear-cut. But what is clear is that the extensive overuse of drugs and high-tech medical procedures is a matter for concern. Rapidly rising health care costs in China have probably been one of the factors behind the fall in demand for health care over the last 10 years. And they have made health care increasingly unaffordable for China’s poor families.

China's health system also displays considerable inequities in, for example, utilization and outcomes between rural and urban areas, and across income groups. How far these can be blamed on providers is unclear-utilization and outcomes reflect demand-side and supply-side factors. What can be said, however, is that in recent years—in contrast to the 1960s—-the health service delivery system in urban areas has developed much faster than in rural areas, and there is a growing gap in quality of care between rural and urban areas.

All in all, the performance of China's health care providers-like providers in many countries—shows considerable room for improvement. What explains this weak performance? And how can the government improve it?

\section{DOES OWNERSHIP MAKE A DIFFERENCE?}

One hypothesis—often expressed in China—is that poor provider performance reflects the heavy emphasis on public ownership above village level. The international evidence on whether ownership matters—mostly from the United States—is mixed. Some studies suggest ownership and profit-status of providers do not make a difference- that ultimately it is other 
factors that determine performance. ${ }^{6}$ Other authors disagree and conclude that technical quality is lower and mortality higher in for-profit hospitals. ${ }^{7}$ While many studies focus on the difference between for-profit and non-profit hospitals, there is less evidence on the differences related specifically to ownership. Some studies suggest that public hospitals perform worse than private ones, but this may simply reflect their status as "providers of last resort", whereby they are forced to handle more complex cases.

The limited evidence available from the Chinese health sector is consistent with the international literature: it suggests that ownership probably matters less than people often think. For-profit and public providers are just as likely as one another to over-prescribe drugs, and forprofit providers are just as likely to deliver preventive activities as public ones, provided they are paid properly to do so. ${ }^{8}$ Patients often express a high level of satisfaction with the responsiveness of private providers, but also express some concern about their qualifications and motivations. ${ }^{9}$ There is some evidence that for-profit providers in China have a more efficient management. However, this reflects at least in part the fact that public providers are constrained by the relevant stakeholders in a way that private providers are not. It may not be ownership per se that makes the difference, but rather the willingness of stakeholders to stay at arm's length from day-to-day decision-making.

All of this has important implications for the reform agenda in China's health sector. Provider behavior is influenced by a wide range of factors—-financing, autonomy, market structure, accountability arrangements, etc. Ownership may be related with these factors, but often it is not the primary determinant. As a consequence, privatization is not likely to be the panacea that some in China believe it to be. 


\section{IS COMPETITION THE ANSWER?}

Another commonly heard view in China is that the health sector needs more competition. The international literature suggests extreme caution on this point, and is very clear on one key point: competition for individual patients is not the answer. Patients lack the knowledge to be informed consumers as in a typical market. This blunts competitive pressures, and makes patients vulnerable to exploitation by providers who take advantage of their superior knowledge of medical matters.

What can be potentially useful, however, is competition among providers for contracts from purchasers (e.g. insurers). The evidence is limited, mostly coming again from the U.S., where, for example, competition for Medicare contracts appears to have improved patient outcomes and lower costs. ${ }^{10}$ Elsewhere in the OECD, several other countries-including the Czech Republic, New Zealand, Sweden and the United Kingdom—have experimented with having hospitals compete for contracts. However, as a recent OECD report put it, "[these initiatives] have not achieved the expected results and have run into considerable patient and provider opposition. However, as these experiments were discontinued after a relatively short period, more time may have been needed for positive results to appear". ${ }^{11}$

Contracting is likely to work better when the contract can specify quantity and quality clearly, both can be monitored easily, and contracts can be enforced. ${ }^{12,13}$ There has been some success with contracting public health interventions, such as malaria control programs, nutrition programs (Senegal) and reproductive health programs (Bangladesh) ${ }^{14}$ These services are relatively straightforward for contractual specification. Contracting for appropriate clinical care, by contrast, is often more challenging. ${ }^{15}$ 
An area where health care sector competition may prove more straightforward is in input markets. For example, in many countries there is a competitive labor market for hospital managers, who attract similar compensation packages from both for-profit and non-profit hospitals. Similarly, competition in the markets for physicians, nurses, and medical equipment and materials, and support services such as maintenance, catering, cleaning, and laundry can help to allocate resources in a way that rewards, and thus stimulates, improved performance. Input markets are generally less prone to 'market failure', since they often feature organized purchasers and suppliers with similar information and market power.

The evidence to date from China on the benefits of competition-be it competition between providers or in markets for inputs-is very limited and research on this topic would be useful. In the meantime, policy reform in China could usefully learn from the lessons of international experience. The performance of China's health sector will almost certainly not be improved by encouraging competition between providers for individual patients. In fact, such a policy is likely to exacerbate existing problems. Where competition could be useful is in a market for purchaser contracts, and in input markets. That would mean developing the purchasing capacity of insurers such as BMI and NCMS-an issue we will return to later. Careful monitoring will be vital, not least to ensure there are no unwanted side-effects. In order to realize the potential benefits of competition in input markets, providers would need be given more autonomy to make decisions about what inputs and services should be contracted for, and from whom to contract. Again, careful monitoring would be vital. 


\section{PRICES AND PROVIDER PAYMENT}

The evidence is not at all clear, then, on how ownership and competition impacts on provider performance. By contrast, what is clear from studies to date is that how providers are paid matters in health care. Furthermore, payment-related incentives can be improved without changing ownership, and without introducing competition.

Providers in China-like providers in many countries-receive payments from three sources. The bulk (over 60\%) comes out-of-pocket payments paid by fee-paying patients. Government subsidies-largely from provincial and county governments, rather than from central government-account for $20 \%$ of health spending. Insurers-largely social insurance agencies such as CMS and BMI, rather than private insurers, such as China Life-account for the remaining $20 \%$.

The prices paid by fee-paying patients are set by government, with the dominant concern being to make sure that basic services are affordable to the whole population. Prices have tended to be set below cost for simple and non-invasive care, and above cost for more complex care. The intention is that patients who need 'basic' care receive it, while patients who want the less basic and more expensive care pay enough for it to enable the provider to cross-subsidize the basic care from their profits on the more expensive care. Government subsidies have been based not on performance or throughput, but rather on staff numbers and the stock of beds. This encourages hospitals to expand their workforce and their bed stock, but not to improve the quality of their care or their efficiency. Health insurers - the final payer-vary in the way they pay providers in China. However, only some have moved beyond fee-for-service (FFS). 
The emphasis on FFS coupled with the distorted price schedule has resulted in providers generating demand for expensive care. Simple and non-invasive care tends to be under-provided, leading to concerns about low-and in some cases_falling coverage of key public health interventions, while high-tech diagnostics are over-provided. This is reflected in the rapid adoption of new technology in China's health sector and the recent rapid growth of hospital revenue per patient episode. It is the latter rather than rising utilization that largely accounts for the rapid growth of health spending in China, which has averaged $12 \%$ per annum in real terms during the 1990s (Fig 1). Because of the markup pricing scheme that has long been in force, drugs are also profitable-hence their over-prescription. China's high average length-of-stay (LOS) is another example of incentives at work-because hospitals that are paid of a FFS basis can claim reimbursement for the additional day, they have an incentive to keep patients in hospital.

Figure 1: Inpatient revenues have been rising largely because of rising costs of care*

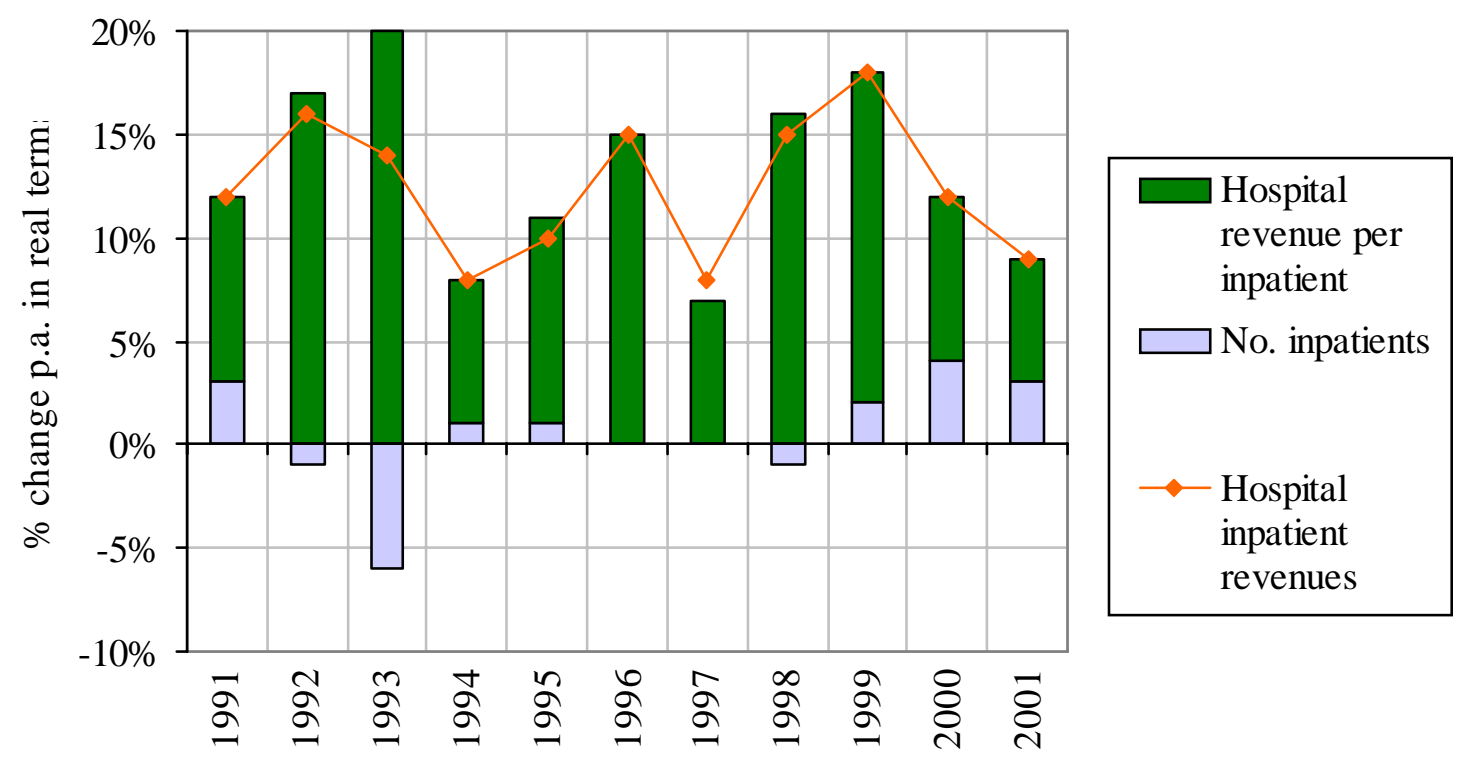

* Source: China National Health Economics Institute China National Health Accounts Digest, 2002. Data refer to large hospitals only. 
Some efforts have been made to improve matters. In 2000, the government sought to reduce the distortions in the price schedule, by increasing the prices of professional services and reducing the price of high-tech care. A study in Shaanxi found that this resulted in a shift in expenditures from high technologies to basic professional services, and a reduction in growth rates of expenditures for secondary and tertiary hospitals, using four diseases as tracers. ${ }^{16}$ However, a study in four provinces of Beijing, Gansu, Shandong and Henan, concluded that high technologies are still highly profitable, encouraging hospitals to acquire high-tech equipment. ${ }^{17-19}$

Reform of drug prices has also begun, but again apparently with mixed results. Starting in 2000, the central government began to change its drug pricing policy from controlling the entire range of prices for all pharmaceuticals to controlling retail prices for selected products only. One rationale for the reform was that cost-effective drugs would be utilized more if the prices of these drugs are reduced. ${ }^{20}$ The government declared that retail prices should be reduced by an average of $15 \%$ before the end of $2001 .{ }^{21}$ However, in a recent study—albeit one based on a small sample-it was found that the new drug-pricing policy did not work in controlling drug expenditures, because hospitals could maintain high drug revenues by increasing drug utilization and shifting utilization from drugs whose prices had been reduced to high-price drugs. ${ }^{22}$

Beyond reforms to the price schedule, there have been more radical reforms, involving a switch from FFS to a superior payment method. Some of these efforts have been evaluated. Typically, they have been initiated by insurers or government. Hainan Province, for example, implemented prospective payment for six key hospitals in January 1997. Average expenditure per admission fell below that of the other hospitals that had continued to be paid FFS, and the growth in spending on high-tech services was reduced. ${ }^{23}$ Whether there was any adverse effect on quality is not known. 
Jiujiang, one of the original pilot cities for the new BMI, started out using FFS to pay hospitals, but in late 1996 switched to a fixed charge per inpatient day, having experienced a high rate of growth of medical expenditures under FFS. ${ }^{24}$ In 2001, the province switched again in an attempt to further curb expenditure growth, this time to capitation. ${ }^{25}$ After the switch to capitation, medical expenditure per insured inpatient fell from 2320 yuan to 1778 yuan, and the share of drug spending in total spending fell from $76.5 \%$ to $59.8 \%{ }^{25}$

Zhenjiang, the other BMI pilot ciity, started out using a fixed charge per inpatient day, but in 2001 started to experiment with a DRG-based payment method for 82 diseases. ${ }^{24,26}$ Rates were fixed-hospitals could retain any savings, but bore the loss if actual expenditures exceed the fixed rates. Reimbursement rates for each disease were set according to average expenditure incurred over the previous three years in treating the disease in question, less any unreasonable expenditures. ${ }^{26}$ In Zhenjiang in 2003, the average expenditure for diseases using DRG payment method was $25 \%$ lower than the province average in the same level hospitals. ${ }^{26}$

In subsequent nationwide implementation of BMI, many cities followed the leads of Jiujiang and Zhenjiang in switching to payment methods other than FFS. Many have adopted a fixed charge per inpatient, but not all. For example, in Guangdong Province in 2002, 13 of the 18 municipal cities used this method, two used FFS, two used capitation, and one used a fixed charge per inpatient day. ${ }^{27}$ In some cases, a variety of different payment methods are used alongside a fixed charge per inpatient. In Guanzhou, Zhenjiang, Dalian, Liuzhou, Mudanjiang and Xiamen, DRG and FFS were also used for some specific diseases such as TB, mental disease, and late stage treatment of tumor. ${ }^{28}$ Less evidence on impacts is available for these cities than for Jiujiang and Zhenjiang. 
In the rural sector, there has also been some experimentation with alternatives to FFS, though no evidence on impacts appears to exist. In two counties of Xinjiang, the county government—-through the CMS fund—paid 40-50 yuan per month to each village practitioner. In return, the village doctors provided free diagnostic and treatment, except for certain itemssuch as a delivery—for which they received additional fees. ${ }^{29}$ In Kuanyang township of Guizhou Province, all contract village clinics were managed by township health centers for purchasing and charges for drugs. Payment for village practitioners included three parts: a basic salary, an indicator-based bonus (indicators included the number of home visits and patient satisfaction), and a performance-based bonus (performance included cost containment). The basic salary was 300 yuan a year for each practitioner. ${ }^{30}$ In Wushe county in Henan, each household contributed 10-30 yuan to form the fund. With the total fund, village clinical practitioners were contracted to provide free physical examinations once a year. The CMS member is entitled to receive discounted services ranging $15-20 \%$ for defined services in village and township health facilities. ${ }^{31}$ In Wuxue county in Hubei, village doctors and THCs are paid a capitation payment by CMS, and in return they are expected to provide defined basic health services to CMS members with the fixed allocation of the fund (10 yuan for the village and 10 yuan for the THC a year). If the CMS fund is not balanced, $70 \%$ of the deficit should be covered by THCs and the rest is covered by village clinics. ${ }^{29,32,33}$ In two counties of Gansu Province, DRG payment has been used by the CMS. ${ }^{34}$

Interestingly, some providers in China have of their own volition moved away from FFS. For example, some hospitals have introduced diagnosis-related groups (DRGs) for fee-paying patients, in the hope that they may be able to attract more business by developing a reputation for transparency in pricing. The earliest documented experiment of DRG pricing was in three hospitals in Ha'erbin county in Heilongjiang in $1994 .{ }^{35}$ By the end of 2000, 16 hospitals in 
Ha'erbin had started using DRGs. ${ }^{36}$ Since then, DRG use has been reported in many other parts of China, including Jining county in Shandong, Fouzhou county in Fujian, Wen county in Henan, Tangshan county in Hebei, Hangzhou and Leqing counties in Zhejiang, Zhenjiang county in Jiangsu, and Hongya county in Sichuan. ${ }^{37}$ There is, unfortunately, little evidence on the consequences of these initiatives. However, the evidence that does exist suggests that the adoption of DRGs brought down costs. In the Red Cross Hospital of Ha'erbin, total expenditures for acute appendicitis decreased after implementation of DRGs, and the proportion of drug expenditures in total expenditures decreased from $50 \%$ to $15 \% \cdot{ }^{36}$ In Jining Medical College Hospital, for the five diseases monitored, total expenditure per case decreased by 3050\% following implementation of DRGs, drug expenditure per case fell by 34-64\%, and average length of stay fell by 0.4-2 days. ${ }^{38}$ Nothing appears to be known about the effects of DRG adoption on other dimensions of health care, including quality of care and "cream skimming" (providers deliberately avoiding the more complicated cases within each diagnostic group).

There have also been some experiences with alternative provider payment methods for outpatient care. Shanghai switched to a capitation based payment for outpatient care for the government insurance program. ${ }^{39}$ While findings indicate a slow-down in cost-escalation, reform design and available data do not permit a rigorous assessment—a problem that arises with many payment reforms in China as well as in other countries.

In many cases, provider payment reforms have been introduced in conjunction with other health system reforms. For example, Meng et al. report on a comparison between Nantong, an urban health insurance pilot city that implemented both provider payment reforms and new forms of contracting, and Zibo, a city that did not implement reforms. ${ }^{40}$ They find a smaller cost- 
increase in Nantong, without measurable impact on quality. Similar results have been found in other studies. ${ }^{41}$

Moving completely away from FFS to a fully prospective payment system can be risky— providers may skimp on quality unless the payer quality thresholds are laid down, and unless quality and quantity can be monitored effectively. Some prospective payment systems also create incentives for risk selection. ${ }^{42}$ In China, some steps have been taken to promote quality and deter misconduct by hospitals. For example, in Qingdao, where a global budget has been used, payments to hospitals have been reduced if they admitted fewer than $95 \%$ of the number of patients they had admitted the previous year. ${ }^{43}$ A mixed payment system—combining FFS and prospective payment—offers an alternative approach to solving this problem, and has become popular across the OECD.

What are the implications for policy reform? There seems to be considerable scope for improving provider performance in China through carefully designed and phased payment reform. This would be most effective if combined with strengthened purchasing functions of insurers. On the pharmaceutical side, separation of the prescribing and dispensing functions has the potential of reducing adverse provider incentives. Experience from Taiwan and elsewhere has, however, shown that such reforms have to reconcile many strong interests, making effective reform difficult. ${ }^{44}$

\section{ORGANIZATION MATTERS}

The performance of any delivery system reflects a number of organizational choices. For example, a well-functioning referral system lowers costs and enhances equity. ${ }^{45}$ In its transition from the old system, China lost this: patients now choose whichever level of provider they can 
afford, so the higher-level (e.g. provincial and county) hospitals are overloaded with higherincome patients, and the lower-level hospitals (e.g. township) are underutilized and patronized by mostly low-income patients.

But other aspects of how the delivery of health care services is organized also matter. Overlapping functions and fragmented service delivery responsibilities need attention. For example, family planning institutions, township health centers, and maternal and child health facilities in China have overlapping functions. $\mathrm{MOH}$, military, SOE and other enterprise hospitals all provide similar services in an uncoordinated manner. And there are also questions about the roles and responsibilities of different levels of government in service delivery. Several studies have found that decentralization in China has had a negative impact on delivery, especially equity of services between richer and poorer regions. ${ }^{46}$

Finally, quality and efficiency are also affected by the internal structure and management of delivery organizations. Many hospitals lack effective quality control system, with supervision responsibilities scattered across different departments and agencies. Moreover, financial management systems and personnel policies—e.g. in relation to compensation—affect incentives and provider performance. The study in Zibo and Nantong found that the main factors influencing unit cost, LOS, and other efficiency indicators were the bonus system, competition for hospital positions, selection of staff, and the accountability system.

\section{CONCLUSIONS}

Current performance by Chinese health care providers leaves room for improvement, in terms of quality, responsiveness to patients, efficiency, cost escalation, and equity. The literature also suggests that these problems will not be solved by simply shifting ownership to the private 
sector, or by simply encouraging providers-public and private- to compete with one another for individual patients.

But our review also contains some important positive messages too. Active purchasing by organized purchasers can be an effective way to affect system incentives. In both the urban and rural areas, social insurers-e.g. BMI and NCMS—and other purchasers could promote improvement in service delivery through selective contracting, mixed payment methods with quality bonuses, drug use monitoring and formularies, and effective gate-keeping.

While some of the problems observed in the Chinese health sector today are due to excessive or inappropriate government intervention, other problems arise from the government doing too little. Information asymmetries and other market failures call for effective government regulation in the health sector. Regulation of advertising can play an important role in protecting population health and reducing information asymmetries-e.g. in relation to tobacco. There is also an important place for regulation of behavior in insurance and health care markets, such as preventing price collusion and “cream-skimming”, controlling quality, protecting patient privacy, and providing information. In health systems that allow a prominent role for markets in shaping the delivery system, antitrust policy is a crucial tool for establishing a "fair playing field".

In most health systems, the government also plays an important role in relation to the health workforce. China clearly has major challenges in this area. One challenge, already noted, lies with the quality of its medical personnel. So far, the focus has been largely on increasing the quantity of health workers. A clear challenge now is to increase quality, and to ensure that the distribution of health workers reflects need. But it is not just China's medical skills that need improving. Its health sector lacks managers, quality assurance personnel, and other key groups. 
For example, whatever the role of the market and government in service delivery, a credible system of supervision and certification of provider competence is necessary.

In summary, Chinese experience matches theory and global evidence, namely that system-wide incentives shape provider performance. Fortunately, both Chinese and international experience offer some clear lessons on how these incentives can best be harnessed. Unfortunately, there are no quick fixes. The interaction of incentives calls for a package of complementary reforms, including strengthened purchasing and provider-payment reforms, effective sector-neutral regulation, appropriate vertical and horizontal integration of health care institutions, and improved provider management. 


\section{References}

1. Wang G, Xu H, Jiang M. Evaluation on comprehensive quality of 456 doctors in township hospitals. Journal of Health Resources 2003;6(3):72-74.

2. Zhang X, Feng Z, Zhang L. Analysis on Quality of Prescription of Township Hospitals in Poor Areas. Journal of Rural Health Service Management 2003;23(12):33-35.

3. Liu X, Mills A. Evaluating payment mechanisms: how can we measure unnecessary care? Health Policy and Planning 1999;14(4):409-13.

4. Zhuang N, Tang S. Application and Research on Methods of Adjustment of Medical Quality and Case Mix in Measurement of Hospital Service Efficiency. Journal of Health Resources 2001;4(3):127-129.

5. Cai Z, Chen P, Deng H. Elementary Investigation on Current Condition of the Degree of Customer Satisfaction in Medical Services in Guangzhou City. Journal of Hospital Statistics 2002;9(1):24-25.

6. Sloan F. Not-for-Profit Ownership and Hospital Behaviour. In: A J Culyer, J P Newhouse, eds. The Handbook of Health Economics. Amsterdam: Elsevier North-Holland, 2000: 1141-1174.

7. Devereaux P, Choi P, Lacchetti C, et al. A systematic review and meta-analysis of studies comparing mortality rates of private for-profit and private not-for-profit hospitals. Canadian Medical Association Journal 2002;166(11):1399-406.

8. Meng Q, Liu X, al. e. Comparing the services and quality of private and public clinics in rural China. Health Policy and Planning 2000;15(4):349-356.

9. Kin LM, Hui Y, Tuohong Z, Zijun Z, Wen F, Yude C. The role and scope of private medical practice in China: Commissioned by UNDP, WHO, MOH China. mimeo., 2002.

10. Kessler DP, McClellan M. Is Hospital Competition Socially Wasteful? Quarterly Journal of Economics 2000;115:577-615.

11. Docteur E, Oxley H. Health-Care Systems: Lessons from the Reform Experience. OECD Health Working Paper. Paris: OECD, 2003.

12. Hart O, Shleifer A, Vishny RW. The Proper Scope of Government: Theory and an Application to Prisons. Quarterly Journal of Economics 1997;November:1127-1161.

13. World Bank. World Development Report 2004: Making Service Work for Poor People. Oxford: Oxford University Press and the World Bank, 2003.

14. World Health Organization. The World Health Report 2000: Health systems--improving performance. Geneva: World Health Organization, 2000.

15. Harding A, Preker A, eds. Private Participation in Health Services. Washington, DC: World Bank, 2003.

16. Jin C, Wang L, Peng Y. New fee schedule and the inpatient expenditures for four diseases. Price and Market 2002;9:37-39. 
17. Meng Q, Bian Y, Sun Q, al. e. Improving the pricing system for health care (I). Chinese Journal of Health Economics 2002;5:31-34.

18. Bian Y, Zhuang N, Meng Q, Yu S. Cost and efficiency of use of PET. Chinese Journal of Health Economics 2002;8:15-17.

19. Sun Q, Ge R, Meng Q, al. e. Cost and efficiency of PET/CT. Chinese Journal of Health Economics 2005;2:37-41.

20. China State Commission of Planning and Development. Reforms of drug pricing policy, 2000.

21. China State Drug Administration. National actions in reducing drug prices: Public notice, 2003.

22. Meng Q, Cheng G, Silver L, Sun X, Rehnberg C, Tomson G. The impact of China's retail drug price control policy on hospital expenditures: a case study in two Shandong hospitals. Health Policy Plan 2005;20(3):185-96.

23. Yip W, Eggleston K. Addressing government and market failures with payment incentives: Hospital reimbursement reform in Hainan, China. Social Science \& Medicine 2004;58:267-277.

24. Meng Q. The Impact of provider payment reforms on cost containment. Chinese Health Economics Research 2002;9:18-20.

25. Jiujiang Health Insurance Office. The "413" urban health insurance arrangement. Jiujiang, Jiangxi province: Project Report, 2004.

26. Wu A, Li Y, Zhang Y, Cheng X. DRG-based payment reform for urban health insurance scheme. Chinese Journal of Health Economics 2004;9:38-39.

27. The Project Team. Investigation of Payment methods in Guangdong: Project Report of Guangdong Provincial Department of Science and Technology, 2003.

28. Lin Q. Adjustment of payment methods for urban health insurance schemes. Chinese Advanced Hospital Management 2004;7:23-25.

29. Hu S. Overview of CMS models in China. Chinese Journal of Primary Health Care 2003;9:1-6.

30. Wang F. Improve rural NCMS in poor areas. Guizhou Finance and Economics Journal 2003;6:62-64.

31. Health Bureau of Wushe County. Serving the establishment of rural household contract system. Chinese Rural Health Care Management 2002;7:28-30.

32. Wang B, Wang L, Li N, Liu X. CMS in Wuxue for 40 years. Chinese Rural Health Care Management 2004;1:10-13.

33. Wang Z, He S, Zhou D. Why CMS in Wuxue can be sustained and developed. Chinese Rural Health Care Management 2003;2:25-26.

34. Gansu Provincial Department of Health. Personal Communication with Prof. Meng Qinqyue, 2005. 
35. Liu S, Zheng M, Yang S, Wang S. Analysis of DRG-based charges. Chinese Health Economics Research 1999; 5:39-40.

36. Yang Z, Zhao Z, Liu T. The impact of DRG-based user charge on expenditure control. Chinese Journal of Health Economics 2001; 4:25-26.

37. Bai Y. About DRG payment reforms. Modern Medicine 2004;8:25.

38. Yin A. The impact of DRG user charge on hospital length of stay and expenditures. Discussion paper: Shandong University, 2004.

39. Yang W, Xuan L, Shen R, Zhang M, Gu S. The Effectiveness Evaluation of Capitaiton in Outpatience Items of Governmental Employee's Insurance System. Chinese Health Economics 1999;12.

40. Meng Q, Rehnberg C, Zhuang N, Bian Y, Tomson G, Tang S. The impact of urban health insurance reform on hospital charges: A case study from two cities in China. Health Policy 2004;68(2):197-209.

41. Liu G, Cai R, Xiong X. Reform of Medical Insurance System in Chinese Cities: Discussion on Equity of Cost Allocation. Journal of Economics(Quarterly) 2003;2(2):435-452.

42. Newhouse J. Reimbursing Health Plans and Health Providers: Selection versus Efficiency in Production. Journal of Economic Literature 1996;34:1236-1263.

43. Qingdao Municipal Department of Labor and Social Security. Payment arrangements for contract hospitals.: Policy Document No 52, 2003.

44. Chou YJ, Yip WC, Lee CH, Huang N, Sun YP, Chang HJ. Impact of separating drug prescribing and dispensing on provider behaviour: Taiwan's experience. Health Policy and Planning 2003;18(3):316-29.

45. Gerdtham U, Jonsson B. International Comparisons of Health Expenditure. In: A J Culyer, J P Newhouse, eds. The Handbook of Health Economics. Amsterdam: Elsevier North Holland, 2000: 11-53.

46. Tang S, Bloom G. Decentralizing rural health services: A case study in China. International Journal of Health Planning and Management 2000;15(3):189-200. 